\title{
Evaluation of Standardization of Transfer of Accountability between Inpatient Pharmacists
}

\author{
Vivian Tsoi, Norman Dewhurst, and Elaine Tom
}

\begin{abstract}
Background: A compelling body of evidence supports the notion that transfer of accountability (TOA) improves communication, continuity of care, and patient safety. TOA involves the transmission and receipt of information between clinicians at each transition of care. Without a notification system alerting pharmacists to patient transfers, pharmacists' ability to seek out and complete TOA may be hindered. A standardized policy and process for TOA, with automated workflow, was implemented at the study hospital in 2015, to ensure consistency and timeliness of documentation by pharmacists.
\end{abstract}

Objective: To evaluate pharmacists' adherence to and satisfaction with the TOA policy and process.

Methods: A retrospective audit was conducted, using a random sample of individuals who were inpatients between June 2014 and February 2016. Transition points for TOA were identified, and the computerized pharmacy system was reviewed to determine whether TOA had been documented at each transition point. After the audit, an online survey was distributed to assess pharmacists' response to and satisfaction with the TOA policy and workflow.

Results: Before the TOA workflow was implemented, TOA documentation by pharmacists ranged from $11 \%(10 / 93)$ to $43 \%$ (48/111) of transitions. Eight months after implementation of the workflow, the rate of TOA documentation was $87 \%$ (68/78), exceeding the institution's target of $70 \%$. Of the 32 pharmacists surveyed, most were satisfied with the TOA policy and agreed that the standardized workflow was simple to use, increased the number of TOAs provided and received, and improved the quality of completed TOAs. Respondents also indicated that the TOA workflow had improved patient care (mean score 4.09/5, standard deviation 0.64).

Conclusions: The standardized TOA policy and process were well received by pharmacists, and resulted in consistent TOA documentation and a TOA documentation rate that exceeded the institutional target.

Keywords: transfer of accountability, standardization, policy, documentation, pharmacist

\section{Can J Hosp Pharm. 2018;71(2):99-104}

\section{RÉSUMÉ}

Contexte : Un nombre imposant de données probantes viennent appuyer l'idée que le transfert de responsabilité (TDR) améliore la communication, la continuité des soins et la sécurité des patients. Le TDR consiste en la transmission et la réception d'information entre cliniciens à chaque transfert des soins. Sans système de notification informant les pharmaciens d'un transfert de patient, leur capacité de trouver et de réaliser un TDR pourrait être restreinte. Une politique et un processus normalisés de TDR, comprenant une automatisation du flux de travaux, ont été mis en place en 2015 dans l'hôpital à l'étude afin d'assurer que la consignation par les pharmaciens soit uniforme et opportune.

Objectif : Évaluer dans quelle mesure les pharmaciens respectent la politique et le processus de TDR, et en sont satisfaits.

Méthodes : Un audit rétrospectif a été mené à l'aide d'un échantillon aléatoire composé de patients hospitalisés entre juin 2014 et février 2016. Les points de transition pour le TDR ont été recensés et le système informatique de la pharmacie a été consulté pour déterminer si le TDR avait été consigné à chaque point de transition. Après l'audit, un sondage en ligne a été envoyé aux pharmaciens pour évaluer leurs réactions à l'égard de la politique de TDR ainsi que du flux de travaux correspondant et pour connaître leur degré de satisfaction.

Résultats : Avant la mise en place du flux de travaux associé au TDR, la fréquence de consignation du TDR par les pharmaciens variait entre $11 \%$ $(10 / 93)$ et $43 \%(48 / 111)$ des transitions. Huit mois après la mise en place du flux de travaux, le taux était de $87 \%$ (68/78), dépassant ainsi la cible de $70 \%$ fixée par l'établissement. Parmi les 32 pharmaciens sondés, la plupart étaient satisfaits de la politique de TDR et ils estimaient que le flux de travaux normalisé était simple à suivre, qu'il augmentait le nombre de TDR reçus et fournis et qu'il améliorait la qualité des TDR menés à terme. Les pharmaciens ont aussi indiqué que le flux de travaux associé au TDR avait amélioré les soins aux patients (score moyen de 4,09/5, écart-type de 0,64).

Conclusions : La politique et le processus normalisés de TDR ont été bien reçus par les pharmaciens et ont permis d'obtenir une harmonisation de la consignation du TDR et un taux de consignation du TDR qui dépassait la cible de l'établissement.

Mots clés : transfert de responsabilité, normalisation, politique, consignation, pharmacien 


\section{INTRODUCTION}

$\mathrm{R}$ outine transfer of accountability (TOA) should occur between pharmacists to ensure patient safety and continuity of care. ${ }^{1}$ Although no universal definition for TOA exists, general principles include the transfer of duties, obligations, and patient information from one health care provider to another at each transition of care. In recent years, TOA has gained greater momentum. As of 2007, the World Health Organization has made communication during patient handover 1 of its 9 safety priorities. ${ }^{2}$ For Canadian pharmacists, the National Association of Pharmacy Regulatory Authorities has not provided guidance on best practices for TOA. Moreover, there is limited literature on TOA completed by pharmacists.

Integrated systems and processes are required for accurate documentation of information related to TOA. ${ }^{3,4}$ One analysis of incident reports related to clinical handover showed that patients were transferred from one service to another without adequate TOA in 29\% of cases, and rates of omission of critical information varied between $14 \%$ and $19 \% .^{5}$ The authors concluded that a structured, standardized approach to handover was required to prevent unintentional data omissions. ${ }^{5}$ This approach was reinforced by the American College of Clinical Pharmacy (ACCP), ${ }^{6}$ which advised that various process measures (i.e., acts completed by practitioners that are directed toward and performed for the patient) should be used to identify and maintain the quality of pharmacist clinical services. Of note, the ACCP proposed that optimal care transitions should begin with pharmacist-led medication reconciliation and should proceed with formal documentation in the patient's medical record, patient counselling, and ideally verbal (or alternatively written) hand-off of therapeutic problems to the incoming pharmacist. Ultimately, this workflow encourages consistency and is recommended for every level of patient transfer. ${ }^{6}$

In December 2010, the US National Transitions of Care Coalition released a position paper on health information technology and care transition. In this paper, the Coalition recommended a minimum data set for TOA, with a functional electronic health system for pharmacists, to enable standardization, good communication, accountability, and care coordination. ${ }^{7}$

In July 2014, a TOA policy for all health disciplines was implemented at the authors' institution, along with a corporate TOA target of $70 \%$. The policy required that TOA be communicated for each internal transition point, with documentation in the patient's medical record using a discipline-specific DARP format (i.e., data, assessment, response, and plan). Although TOA was already occurring among pharmacists, the extent and consistency of documentation of TOA completion was below institutional targets. Therefore, a pharmacy-specific TOA policy and procedure, which was aligned with the health disciplines policy and accompanied by an automated workflow, came into effect on July 16, 2015.
The current study evaluated the utility of the standardized policy and process, with its associated automated workflow, in improving the frequency, consistency, and timeliness of TOA documentation by inpatient pharmacists.

\section{METHODS}

This study was part of a quality improvement initiative completed within the Pharmacy Department at St Michael's Hospital, a large health care institution in Toronto, Ontario. The institution is an urban, tertiary care teaching hospital with 463 acute care inpatient beds. On weekdays, most of the hospital's units are staffed with at least one clinical pharmacist or specialist. The Pharmacy Department has a designated electronic pharmacy system that processes all medication orders (Cerner Pharmacy, formerly known as Siemens Pharmacy).

The TOA workflow introduced in July 2015 is outlined in Figure 1 . The dispensary pharmacy system for inpatients prints a "Notice of Transfer" label each time a patient is transferred between 2 locations within the hospital. This label shows the patient's name, hospital encounter number, location of origin, and destination location (unit and bed number). A pharmacy technician collects these labels and gives them to the dispensary pharmacist for processing. The dispensary pharmacist then opens an "intervention" within the electronic pharmacy system, notifying the receiving pharmacist of the patient transfer. This intervention (i.e., task cue functionality) is an electronic tool used to identify issues for follow-up by a pharmacist. Finally, the dispensing pharmacist initials the "Notice of Transfer" label, which is filed by the pharmacy technician.

The presence of a TOA intervention both cues and places the onus on the receiving pharmacist to seek out TOA from the transferring pharmacist. TOA may be completed verbally, by paper-based communication, or by electronic means (e.g., secure and confidential institutional e-mail). The receiving pharmacist is required to document receipt of the TOA, even if no issues requiring follow-up are present at the time of transfer. As part of the standardization process, a TOA documentation template was built into the electronic pharmacy system. This template was intended to supplement standard electronic pharmacist documentation. At a minimum, the following 5 pieces of information are required: reason for admission, whether medication reconciliation was completed, past medical history, assessment and current issues, and care plan with to-do list.

Within the pharmacy system, the receiving pharmacist must document that TOA was received and must close the previously opened intervention. Pharmacists review their electronic interventions at the beginning and the end of each business day and periodically throughout the day. In addition, they may run a report indicating TOA interventions that are active. The receiving pharmacist should then document the following information: the fact that TOA was completed, the name of the pharmacist providing TOA, and the name of the pharmacist who received 


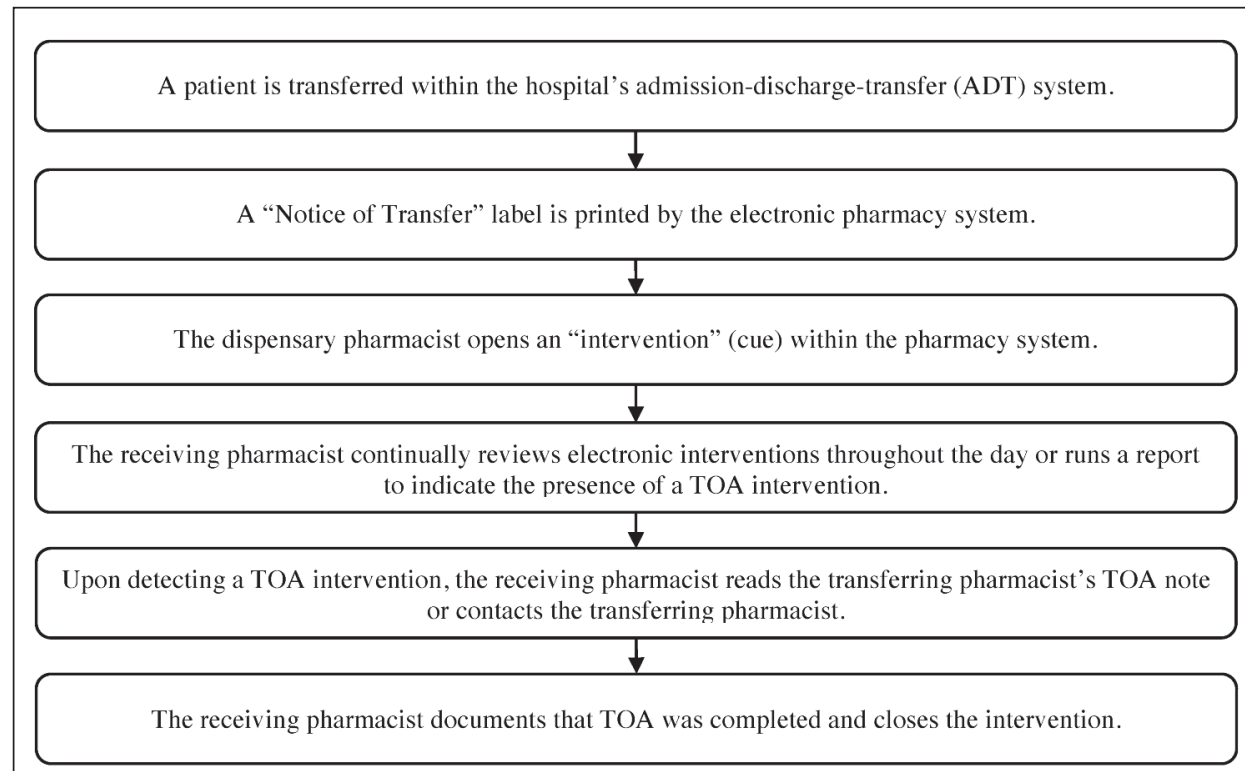

Figure 1. Process for transfer of accountability (TOA) implemented in July 2015 at the study hospital.

TOA (including the person's professional designation, i.e., $\mathrm{RPh}$ ). Ideally, TOA documentation should occur within 1 business day when full unit coverage is available. In the absence of full clinical coverage, documentation of TOA should occur within 3 business days from the day of transfer.

For the current study, electronic patient charts were audited for consecutive 3-month periods from June 2014 to February 2016, to determine pharmacists' compliance with the TOA policy. Random samples of inpatients were identified from among patients admitted during the prespecified 3-month periods; 4 of these periods occurred before policy implementation, 1 period spanned the implementation date (July 16, 2015), and 2 periods occurred after policy implementation. For each patient chart, all internal TOA transition points were identified, by mapping the patient's location during the hospital stay. A transition point occurred when a patient was transferred between 2 different inpatient units, provided that the transition occurred during pharmacy business hours (from 0800 to 1600) and the patient remained on the new unit for at least $4 \mathrm{~h}$. Exceptions (where formal TOA could not have been done) included transitions on weekends and statutory holidays, and the following types of transfer: to and from the operating room, from the emergency department, to palliative care, and to units where the same pharmacist or pharmacists were providing clinical coverage (e.g., from wards to "step-up" units). After all TOA transition points were identified, the electronic pharmacy system was reviewed to check whether TOA had been documented. The rates of TOA documentation were compared before and after implementation of the TOA policy.
After the February 2016 audit, an online survey was distributed to assess pharmacists' satisfaction with the TOA workflow. Demographic characteristics (e.g., unit where the pharmacist works, self-perceived number of TOAs completed and provided per day), responses to statements about the TOA workflow, and overall satisfaction with the current process were captured in the survey.

\section{RESULTS}

A total of 468 electronic patient charts were audited from June 1, 2014, to February 29, 2016. Before implementation of the health disciplines policy in July 2014, the rate of TOA documentation was unknown. After implementation of the health disciplines policy, the rate of TOA documentation at each transition point steadily improved (Table 1). After introduction of the TOA policy and workflow for pharmacists, the rate of TOA documentation continued to increase, eventually reaching $87 \%(68 / 78)$.

During the latest audit period (December 2015 to February 2016), the largest number of internal transition points occurred for patients admitted to the medical-surgical intensive care unit $(21 / 78$ [27\%]) or general internal medicine (20/78 [26\%]), those transferred from the trauma neurosurgery intensive care unit to the trauma neurosurgery ward (13/78 [17\%]), and those transferred from the cardiovascular intensive care unit to the cardiology ward (12/78 [15\%]).

The online survey asked pharmacists to respond to statements on a 5-point scale, where $1=$ strongly disagree and $5=$ strongly agree. Of the 32 pharmacists who participated in the 
This single copy is for your personal, non-commercial use only.

For permission to reprint multiple copies or to order presentation-ready copies for distribution, contact CHHP at publications@cshp.ca

Table 1. Rates of TOA Documentation by Pharmacists before and after Implementation of a Standardized TOA Policy with Associated Workflow

\begin{tabular}{|c|c|c|c|c|c|c|c|}
\hline \multirow[b]{2}{*}{ Audit Parameter } & \multicolumn{4}{|c|}{ Before Implementation } & \multirow{2}{*}{$\begin{array}{c}\text { Overlap* } \\
\text { Period 5: } \\
\text { Jun-Aug } \\
2015 \\
\end{array}$} & \multicolumn{2}{|c|}{ After Implementation } \\
\hline & $\begin{array}{l}\text { Period 1: } \\
\text { Jun-Aug } \\
2014\end{array}$ & $\begin{array}{l}\text { Period 2: } \\
\text { Sep-Nov } \\
2014\end{array}$ & $\begin{array}{l}\text { Period 3: } \\
\text { Dec 2014- } \\
\text { Feb } 2015\end{array}$ & $\begin{array}{l}\text { Period 4: } \\
\text { Mar-May } \\
2015\end{array}$ & & $\begin{array}{l}\text { Period 6: } \\
\text { Sep-Nov } \\
2015\end{array}$ & $\begin{array}{l}\text { Period 7: } \\
\text { Dec 2015- } \\
\text { Feb } 2016\end{array}$ \\
\hline $\begin{array}{l}\text { Total no. of } \\
\text { charts audited }\end{array}$ & 102 & 135 & 122 & 100 & 100 & 100 & 110 \\
\hline $\begin{array}{l}\text { No. of potential } \\
\text { transition points } \\
\text { for TOA }\end{array}$ & 93 & 107 & 60 & 111 & 136 & 123 & 78 \\
\hline $\begin{array}{l}\text { No. of TOA points } \\
\text { documented }\end{array}$ & 10 & 22 & 24 & 48 & 69 & 97 & 68 \\
\hline $\begin{array}{l}\text { \% of TOA points } \\
\text { documented }\end{array}$ & 11 & 21 & 40 & 43 & 51 & 79 & 87 \\
\hline
\end{tabular}

survey, the majority agreed that the TOA workflow was easy to use (mean score 4.1) (Table 2). Respondents perceived that the new policy had increased the number of TOAs being received (mean score 3.8) and provided (mean score 3.5), and improved the quality of TOAs being completed (mean score 3.8). Overall, pharmacists were satisfied with the TOA workflow (mean score 4.0), and they perceived that the process had improved patient care (mean score 4.1).

\section{DISCUSSION}

The results of this study suggest that implementation of a standardized policy, with an automated workflow, is an effective method to ensure consistency and timeliness of TOA documentation. Given the challenges of limited pharmacist resources and time, TOA may not occur at all transitions of care. Furthermore, a lack of awareness of patient transfers may affect a pharmacist's ability to adequately seek out and complete TOA. To the authors' knowledge, the evaluation of TOA between inpatient pharmacists and the use of an automated workflow for TOA have not been previously described.

Within the pharmacy-specific literature, exploratory studies have been completed in community pharmacies to better understand the attributes of clinical handover. Such studies have included identifying various information hazards (e.g., information overload, underload, or scatter; erroneous information) that may occur, and determining how information is being shared and documented (e.g., verbally or in writing). ${ }^{8,9}$ Other studies have supported the use of standardized systems (e.g., forms and electronic information transfer tools) to enhance continuity of care and to minimize communication gaps between hospital and community pharmacists. ${ }^{10,11}$ In light of these factors, it is clear that standardized processes for documentation are an imperative component of TOA.

In contrast to the fields of nursing and medicine, there is a lack of literature characterizing the clinician handover process in inpatient hospital pharmacy. A common recommendation is the development of minimum data sets, electronic health records, and online modules to standardize information transfer. ${ }^{12,13}$ One major caveat is that these technologies may not be easily transferable to other inpatient areas (e.g., from nursing to pharmacy).

Before implementing the pharmacy-specific TOA workflow and policy, TOA was an expected practice standard for all practitioners at the study hospital. However, there was no standardized notification process or tool for documentation. Pharmacists had to identify for themselves the patients requiring TOA, and there was no mechanism capturing quantitative data regarding TOA. As explored in this study, the use of an automated notification system for patient transfer is novel and has not been previously described. These strengths, coupled with the positive uptake by and general satisfaction of pharmacists, indicate that this framework is a practical strategy for ensuring timely and consistent completion of TOA.

This study had some limitations, including its retrospective, single-centre design, with data collection limited to electronic chart review. Given that the contents and style of TOA documentation were not analyzed, it is difficult to discern whether the quality of information from the transferring pharmacist was clear or sufficient for care optimization by the receiving pharmacist. Nonetheless, the survey results indicate that pharmacists thought the current TOA workflow had improved patient care. In addition, TOA was deemed appropriate if it fell within the timeframes outlined by the TOA policy. Evaluation of the total time needed to complete TOA (i.e., from the point of transfer through to documentation), as a metric of timeliness, may provide further insight for system improvement. Finally, it would be interesting to see whether this pharmacy-based policy and workflow could be modified to function in another clinical setting, and whether it would yield similar results in other areas. Collectively, these insights may inform and further enhance best practices for TOA. 
This single copy is for your personal, non-commercial use only.

For permission to reprint multiple copies or to order presentation-ready copies for distribution, contact CHHP at publications@cshp.ca

Table 2. Results of an Online Survey Assessing Pharmacists' Satisfaction with the New TOA Workflow

\begin{tabular}{|c|c|c|c|c|c|c|c|}
\hline \multirow[b]{2}{*}{ Statement } & \multicolumn{5}{|c|}{ Response; No. of Survey Participants $(n=32)$} & \multirow[b]{2}{*}{$\begin{array}{l}\text { Mean* } \\
\pm \text { SD }\end{array}$} & \multirow[b]{2}{*}{ Skew } \\
\hline & $\begin{array}{l}\text { Strongly } \\
\text { Disagree }\end{array}$ & Disagree & Neutral & Agree & $\begin{array}{c}\text { Strongly } \\
\text { Agree }\end{array}$ & & \\
\hline $\begin{array}{l}\text { The TOA workflow } \\
\text { is easy to use when } \\
\text { working in the } \\
\text { dispensary. }\end{array}$ & 0 & 3 & 3 & 15 & 11 & $4.1 \pm 0.9$ & -0.9 \\
\hline $\begin{array}{l}\text { The TOA workflow } \\
\text { is easy to use on } \\
\text { your clinical unit. }\end{array}$ & 0 & 0 & 5 & 17 & 10 & $4.2 \pm 0.7$ & -0.2 \\
\hline $\begin{array}{l}\text { The standardized } \\
\text { TOA template in } \\
\text { [the electronic } \\
\text { pharmacy system] } \\
\text { assists me in cuing } \\
\text { essential information } \\
\text { that needs to be } \\
\text { communicated } \\
\text { for TOA. }\end{array}$ & 0 & 2 & 17 & 12 & 1 & $3.4 \pm 0.7$ & 0.1 \\
\hline $\begin{array}{l}\text { The number of } \\
\text { TOAs I receive has } \\
\text { increased with the } \\
\text { current workflow. }\end{array}$ & 2 & 3 & 3 & 14 & 10 & $3.8 \pm 1.2$ & -1.1 \\
\hline $\begin{array}{l}\text { The number of } \\
\text { TOAs I provide has } \\
\text { increased with the } \\
\text { current workflow. }\end{array}$ & 1 & 5 & 8 & 12 & 6 & $3.5 \pm 1.1$ & -0.4 \\
\hline $\begin{array}{l}\text { Overall, the quality } \\
\text { of TOA has } \\
\text { improved after } \\
\text { implementing the } \\
\text { current workflow. }\end{array}$ & 0 & 1 & 10 & 14 & 7 & $3.8 \pm 0.8$ & -0.1 \\
\hline $\begin{array}{l}\text { Overall, the current } \\
\text { TOA workflow has } \\
\text { improved patient } \\
\text { care. }\end{array}$ & 0 & 0 & 5 & 19 & 8 & $4.1 \pm 0.6$ & -0.1 \\
\hline $\begin{array}{l}\text { Overall, how } \\
\text { satisfied are you } \\
\text { with the new TOA } \\
\text { workflow? }\end{array}$ & 0 & 0 & 6 & 21 & 5 & $4.0 \pm 0.6$ & 0.0 \\
\hline
\end{tabular}

\section{CONCLUSION}

Although the rate of pharmacist TOA improved substantially after implementation of the policy, more data are required to demonstrate the sustainability of this practice. Future audits will allow for continued confidence in the effectiveness of and adherence to this policy, and will indicate the potential for extension of the workflow to other health disciplines. This study suggests that implementation of a standardized TOA policy, with an automated workflow, is an effective approach to ensure consistency and timeliness of documentation between inpatient pharmacists. This successful combination has enabled TOA documentation rates to far exceed the institutional target.
References

1. American College of Clinical Pharmacy; Hume AL, Kirwin J, Bieber HL, Couchenour RL, Hall DL, Kennedy AK, et al. Improving care transitions: current practice and future opportunities for pharmacists. Pharmacotherapy. 2012;32(11):e326-37.

2. World Health Organization Collaborating Centre for Patient Safety Solutions. Communication during patient hand-overs. Patient Saf Solut. 2007;1(3).

3. Ong SW, Fernandes OA, Cesta A, Bajcar JM. Drug-related problems on hospital admission: relationship to medication information transfer. Ann Pharmacother. 2006;40(3):408-13.

4. Alvarado K, Lee R, Christoffersen E, Fram N, Boblin S, Poole N, et al. Transfer of accountability: transforming shift handover to enhance patient safety. Healthc Q. 2006;9 Spec No: 75-9.

5. Thomas MJW, Schultz TJ, Hannaford N, Runciman WB. Failures in transition: learning from incidents relating to clinical handover in acute care. J Healthc Qual. 2013;35(3):49-56. 
6. American College of Clinical Pharmacy; Kirwin J, Canales AE, Bentley ML, Bungay K, Chan T, Dobson E, et al. Process indicators of quality clinical pharmacy services during transitions of care. Pharmacotherapy. 2012;32(11): e338-47.

7. Health Information Technology Work Group. Improving transitions of care with health information technology [position paper]. National Transitions of Care Coalition; 2010 Dec 10.

8. Chui MA, Stone JA. The prescription handoff in community pharmacy: a study of its form and function. J Am Pharm Assoc. 2012;52(6):e161-7.

9. Chui MA, Stone JA. Exploring information chaos in community pharmacy handoffs. Res Social Adm Pharm. 2014;10(1):195-203.

10. Cesta A, Bajcar JM, Ong SW, Fernandes OA. The EMITT study: development and evaluation of a medication information transfer tool. Ann Pharmacother. 2006; 40(6):1074-81.

11. Fisher J, Macintyre J, Kinnear M, Hudson S. Design and evaluation of a documentation system to support the continuity of pharmaceutical care of day-case oncology patients between hospital and community pharmacists. Int J Pharm Pract. 2006;14(2):149-57.

12. Anderson J, Malone L, Shanahan K, Manning J. Nursing bedside clinical handover - an integrated review of issues and tools. J Clin Nurs. 2015; 24(5-6):662-71.

13. Johnson M, Sanchez P, Zheng C. The impact of an integrated nursing handover system on nurses' satisfaction and work practices. J Clin Nurs. 2016; 25(1-2):257-68
Vivian Tsoi, PharmD, was, at the time this manuscript was written, a student in the Leslie Dan Faculty of Pharmacy, University of Toronto, on a pharmacy research rotation at St Michael's Hospital, Toronto, Ontario. She is currently a Pharmacy Resident at London Health Sciences Centre, London, Ontario.

Norman Dewhurst, BScPhm, PharmD, ACPR, is a Clinical Pharmacy Specialist/Leader, Critical Care at St Michael's Hospital, Toronto, Ontario.

Elaine Tom, BScPhm, is a Clinical Pharmacy Specialist/Leader, Professional Practice at St Michael's Hospital, Toronto, Ontario.

Competing interests: None declared.

\section{Address correspondence to:}

Dr Norman Dewhurst

Pharmacy Department

St Michael's Hospital

30 Bond Street

Toronto ON M5B 1W8

e-mail: dewhurstn@smh.ca

Funding: None received.

Acknowledgement: The authors are grateful for presubmission review of this manuscript by Dr S Kalkar. 